\title{
Impact of external wall insulation thickness on internal surface temperature behaviour
}

\author{
Radoslav Ponechal ${ }^{1, *}$, Daniela Staffenova ${ }^{1}$ \\ ${ }^{1}$ University of Zilina, Faculty of Civil Engineering, Department of Building Engineering and Urban \\ Planning, Univerzitna 1, 01026 Zilina, Slovakia
}

\begin{abstract}
During the last years, the concept of low-energy buildings based on high insulation levels becomes the reality. The aim of this paper is to assess some alternatives of insulated and uninsulated external walls with respect of thermal inertia. The thermal damping factor, phase shift, together with the daily courses of indoor surface temperature of the external wall have been analysed. Analysed surface temperatures show the ability of constructions to accumulate heat gains, which can arise during the day.
\end{abstract}

\section{Introduction}

By design of the material for the perimeter wall structures, the static and thermoinsulating aspect is the most important. If the values of thermal resistance are approximately at the same level, the builders would come to a number of other criteria such as the construction technology or internal environment, created by these construction materials. The role of thermal inertia in creating a high-quality indoor environment is indisputable. Its effects on structures and buildings are manifold and they are expressed by a number of indicators. Many indicators of the thermal inertia impact assessment have been developed and published till today. Most of them are described in the standard EN ISO 13786:2007 [1]. In addition, a dynamic simulation methods are increasingly used for the evaluation. The paper from Italy is to assess the deviation arising by the use of different approaches for the calculation of the dynamic thermal characteristics of an opaque envelope element. The EN ISO 13786 procedure has been firstly applied by decomposing the external forcing temperature by means of the Fourier Transform analysis and the comparison with different approaches, such as Finite Difference Methods and Transfer Function Methods, has been carried out [2]. It concludes that there is a good accord among the Transfer Functions Methods and the Finite Difference Methods as regard periodic thermal transmittance. The time shift calculations show deviations of the order of magnitude of one hour, mainly due to the time discretization of the results.

The college from Eindhoven University of Technology considered the $700 \mathrm{~mm}$ depth ultra-lightweight concrete wall in terms of energy efficiency and thermal comfort [3]. At first, they use the periodic thermal transmittance, which combines the properties of thermal transmittance, time shift and decrement factor in one metric. Analytical validation study

* Corresponding author: radoslav.ponechal@,fstav.uniza.sk 
showed that the conduction finite difference scheme in EnergyPlus is able to predict the transient heat transfer phenomena in ultra-lightweight concrete structures with sufficient accuracy, but users of simulation should carefully select an appropriate simulation tool, because this study has also demonstrated that not all transient heat conduction methods that are used in the widely-used software tools are able to predict the heat transfer in ultralightweight slabs without errors. The results of the dynamic simulation of the house operation were shown on discomfort hours.

Nemecek solved similar problems in the passive house [4]. In his contribution based on simulation calculations of summer overheating, according to the importance he ranks an energy storage capacity of construction in a $4^{\text {th }}$ place, behind heat gains from solar radiation, internal heat gains and ventilation regime. The difference between air temperatures by light-weight or heavy-weight construction is about 1-1.5 K.

\section{Dynamic thermal properties}

Because of the fact that the overheated room temperature is influenced by many factors, it is advisable to look at the comparison of basic dynamic characteristics of building materials separately. The International Standard ISO 13786 describes dynamic thermal parameters of multi-homogeneous-layered walls/roofs based on sinusoidal variations of temperature or heat flow rate on the one hand and constant air temperature on the other hand. The parameters relate cyclic heat flow rate to cyclic temperature variations. These parameters are expressed as complex numbers.

Three groups of parameters for the thermal evaluation of building envelope variants in not air-conditioned buildings are analysed in this work: thermal damping factor (DFs), phase shift (LTs) and behaviour of indoor surface temperature. The thermal damping factor is calculated by

$$
D F s=\frac{\left(\theta_{s i, \max }-\theta_{s i, \text { min }}\right)}{\left(\theta_{s e, \max }-\theta_{s e, \text { min }}\right)}(-)
$$

where $\theta_{\mathrm{si}, \max }$ and $\theta_{\mathrm{si}, \min }$ are the maximum and minimum values of the indoor surface temperature during a day, respectively, and $\theta_{\text {se,max }}$ and $\theta_{\text {se,min }}$ are the maximum and minimum values of the outdoor surface temperature.

The phase shift is defined as:

$$
L T s=t\left(\theta_{s i, \max }\right)-t\left(\theta_{s e, \max }\right)(\mathrm{h}),
$$

where $\mathrm{t}\left(\theta_{\mathrm{si}, \max }\right)$ and $\mathrm{t}\left(\theta_{\text {se,max }}\right)$ are the time, when the indoor surface and outdoor surface temperatures reach their maximums.

\section{Structural variants}

Three wall configurations with four different insulation thicknesses are studied and presented: perforated brick wall (BR), heavy weight concrete wall (HC), porous concrete wall (PC) with thermal insulation made of expanded polystyrene (EPS) or mineral wool (MW). These three wall variants have very similar U-values, but differ from each other in the dimension, material density and thermal conductivity. Each of the wall structures (according to Fig. 1) has some selected different insulation thicknesses. The first variant fulfils the requirement for maximal $U$-values $U_{\max }$, the second variant fulfils desired value $U_{N}$, the third one fulfils recommended value $U_{r 1}$ (considered for the year 2016) and the last 
variant fulfils the final thermal resistance $U_{\mathrm{r} 2}$ (considered for the year 2021) by the STN 73 0540:2012 standard [5]. The wall layers compositions are described in Fig. 1.

\section{Thermal conductivity coefficient and DFs}

The experiment analyses several of the above mentioned external wall compositions with the calculation of thermal damping factor and phase shift of the temperature oscillation, which was conducted on the basis of EN ISO 13786. The results from all calculations are shown in Table 1 and Fig. 4.

Constructions designed for new buildings (with the thermal resistances $U_{r 1}$ and $U_{r 2}$ ) reach significantly higher values of the thermal damping factor than the constructions with minimum requirements for thermal resistance. There are strongly significant differences among the porous concrete wall and the other two alternatives. While by the other insulated walls, the thermal damping factor is as high as it is meaningless, this does not go for the porous concrete wall. Comparing the differences by phase shift, it is necessary to take into account the values of temperature setback, too.
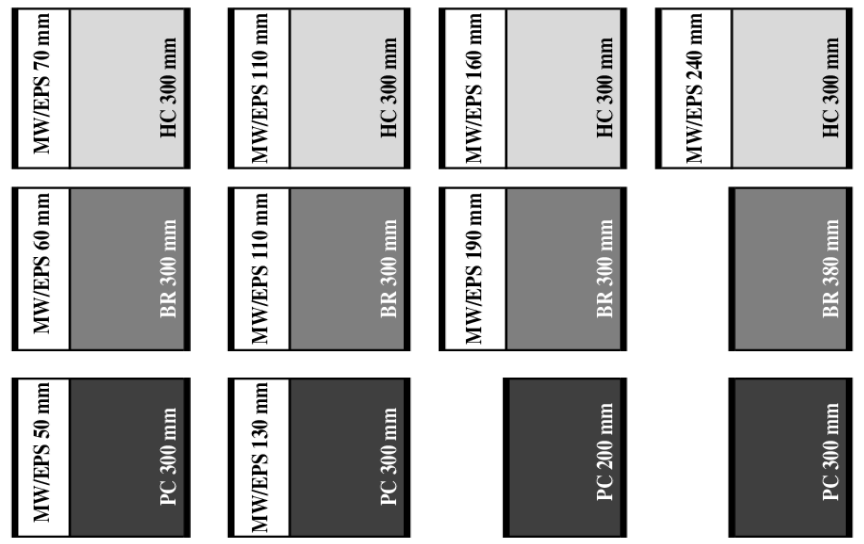

Fig. 1. Evaluated variants of external wall, perforated brick (BR), Porous concrete (PC), heavyweight concrete (HC), expanded polystyrene (EPS) or mineral wool (MW).

Table 1. Results of thermal performance variables reached for evaluated wall structure variants

\begin{tabular}{|c|c|c|c|c|c|c|c|c|c|}
\hline \multicolumn{2}{|c|}{ Structure A } & \multirow{2}{*}{$\frac{U\left(\boldsymbol{W} /\left(\boldsymbol{m}^{2} . \boldsymbol{K}\right)\right)}{0.454}$} & \multirow{2}{*}{$\begin{array}{c}\text { DFs } \\
160.8\end{array}$} & \multirow{2}{*}{$\frac{\boldsymbol{L T S}}{11.7}$} & \multicolumn{2}{|c|}{ Structure $C$} & \multirow{2}{*}{$\frac{U\left(W /\left(\boldsymbol{m}^{2} . \boldsymbol{K}\right)\right)}{0.444}$} & \multirow{2}{*}{$\begin{array}{c}\text { DFs } \\
28.2\end{array}$} & \multirow{2}{*}{$\frac{L T s}{8.1}$} \\
\hline 1 & $H C 300+M W 70$ & & & & 18 & PC 200 & & & \\
\hline 2 & $H C 300+E P S 70$ & 0.454 & 156.1 & 10.5 & 19 & PC 300 & 0.303 & 87.0 & 12.2 \\
\hline 5 & $H C 300+M W 110$ & 0.307 & 294.8 & 13.4 & 20 & $P C 300+M W 50$ & 0.217 & 119.3 & 14.4 \\
\hline 7 & $H C 300+M W 160$ & 0.219 & 575.1 & 15.6 & 22 & $P C 300+M W 130$ & 0.149 & 413.1 & 17.9 \\
\hline 8 & $H C 300+E P S 160$ & 0.219 & 417.8 & 12.9 & 23 & $P C 300+$ EPS 130 & 0.149 & 262.6 & 15.7 \\
\hline 10 & tructure B & $U\left(W /\left(m^{2} . K\right)\right)$ & DFs & $L T s$ & & & & & \\
\hline 11 & $B R 380$ & 0.438 & 261.4 & 18.4 & & & & & \\
\hline 12 & $B R 300+M W 60$ & 0.318 & 333.3 & 17.2 & & & & & \\
\hline 13 & $B R 300+E P S 60$ & 0.318 & 314.9 & 16.1 & & & & & \\
\hline 14 & $B R 300+M W 110$ & 0.211 & 726.3 & 19.3 & & & & & \\
\hline
\end{tabular}




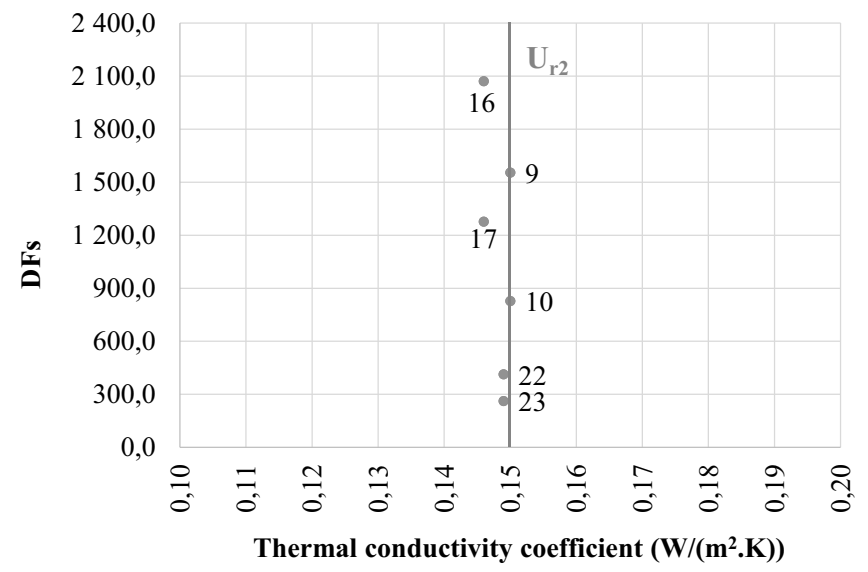

Fig. 2. Thermal damping factor (DFs) for the first group of walls.

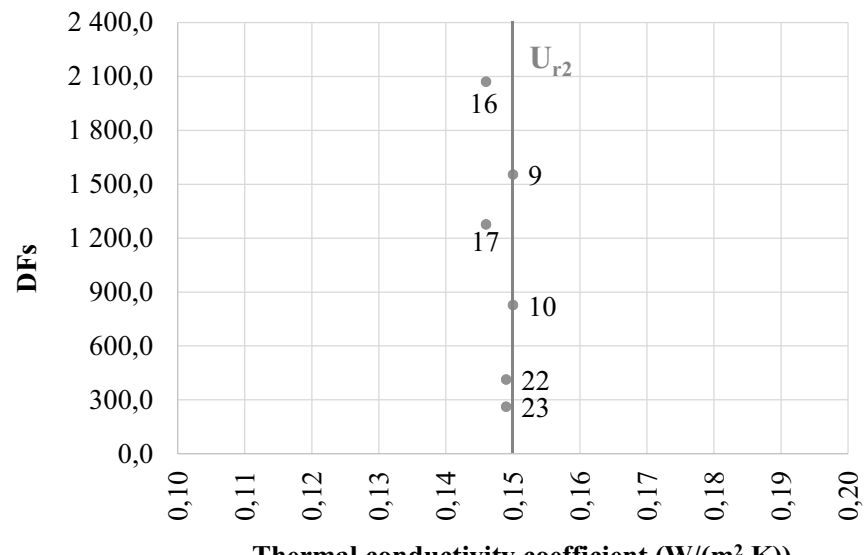

Thermal conductivity coefficient $\left(\mathrm{W} /\left(\mathrm{m}^{2} . \mathrm{K}\right)\right)$

Fig. 3. Thermal damping factor (DFs) for the second group of walls.

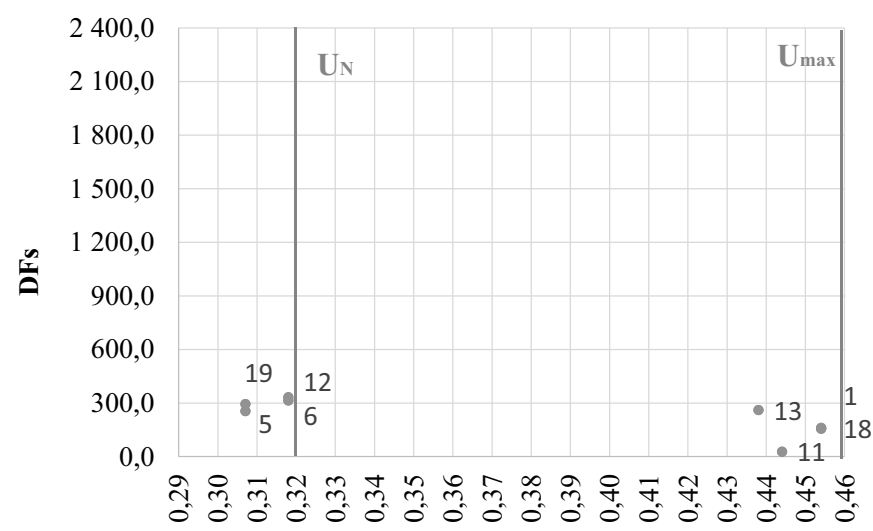

Thermal conductivity coefficient $\left(\mathrm{W} /\left(\mathrm{m}^{2} . \mathrm{K}\right)\right)$

Fig. 4. Thermal damping factor (DFs) for the third group of walls. 
If the value of temperature damping is high (e.g. 200 and more), the phase shift does not play such a role and the inner surface temperature will increase up to 0.5 degree only. It is not so crucial according to the fact at what time this occurs.

Calculations of DF and LT are meaningful only in terms of heat transfer fragment of building envelope constructions (walls, roofs, etc.). The complete image of the building or a room in the building, in terms of summer overheating, will give us only complex calculations of thermal stability or computer simulations.

\section{Simulations of internal surface temperature}

Insulated wall can resist temperatures from the inside and from the outside with a difference. Graphs on Fig. 5 and Fig. 6 show a behaviour of internal surface temperature with 24 hour period change of internal air temperature. The internal air temperature has risen since the morning and it was falling late in the evening. It is a heat conduction behind a non-stationary state. The temperature varies both inside and outside. Lower internal surface temperature means better thermal comfort. The lower internal surface temperature at times of high heat gains means the possibility of accumulating a portion of the heat from the air into the walls.

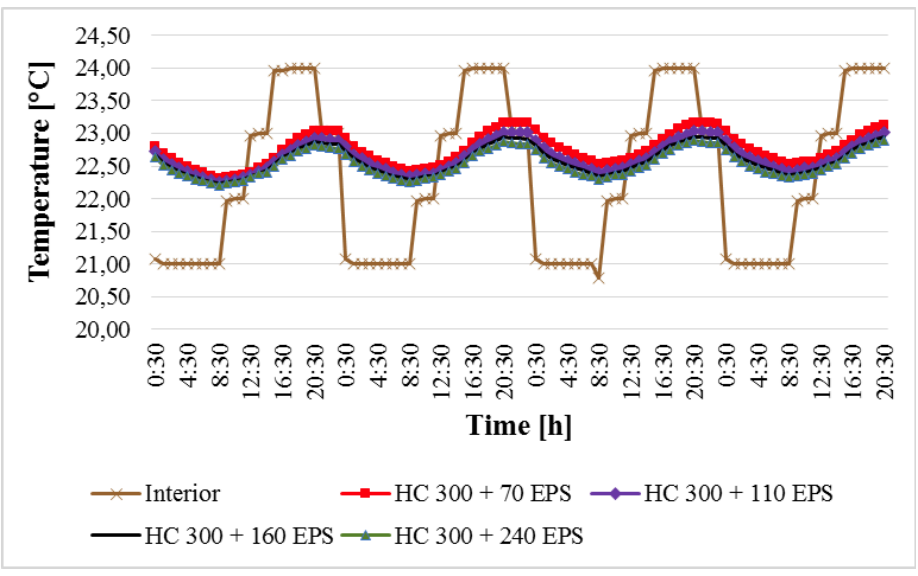

Fig. 5. Internal surface temperature for a heavy weight concrete wall with thermal insulation

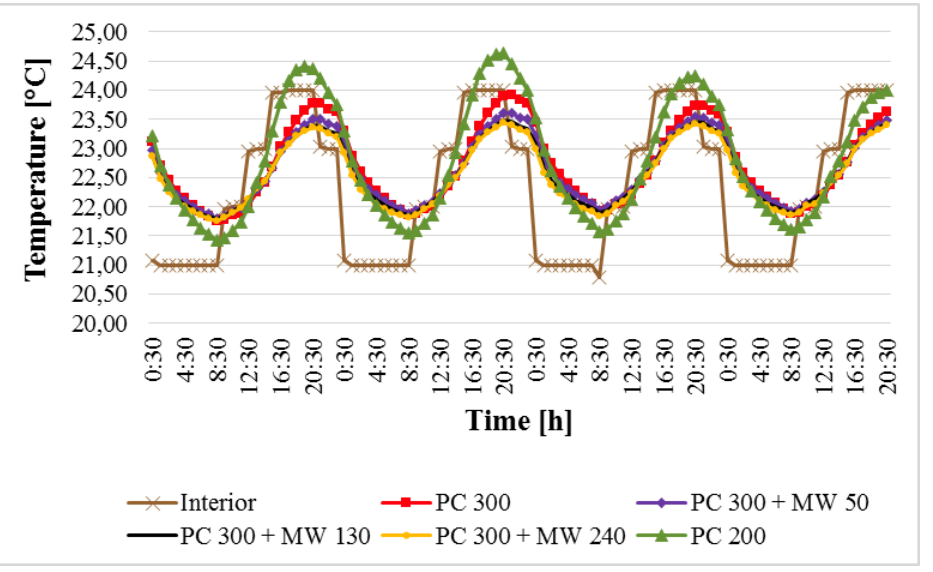

Fig. 6. Internal surface temperature for a porous concrete wall with thermal insulation 


\section{Conclusion}

The impact of external wall on overheating could be defined in two ways: as the structure, through which the heat is transferred from the exterior and it warms the interior or (less usual) as the structure, which contributes to the thermal stability of interior by its accumulative ability.

In the first case, the thermal damping factor, which is very high for the walls in new buildings, is a crucial criterion. Thermal insulation protects the wall from rapid temperature changes. High values of thermal damping factor in insulated walls indicate that its assessment in terms of the daily cycle of temperature rise and fall is an insignificant phenomenon.

A much more substantial contribution can the external wall have on heat loss in the summer season. Heat loss in the summer helps cool the interior at night. However, there is still a conclusion from the contributions $[3,4]$ that the effect on overheating is affected by the control of building ventilation and heat gains.

Another case, when the external walls could affect the interior overheating is its accumulative ability. Integrating of simulation approach could eliminate this imperfection. It appears that the walls insulated in compliance with the new requirements for thermal conductivity coefficient can contribute to thermal stability of the room, because their internal surface temperature remains low even in the evening. The external wall, which holds more heat, has a higher potential to stabilize the interior temperature. However, the thickness of the insulation does not play here a significant role.

Presented results were obtained with the support of the grant project VEGA no. 1/0945/16.

\section{References}

1. STN EN ISO 13786 (2007)

2. A. Gasparella, G. Pernigotto, M. Baratieri, P. Baggio, Energy and Buildings, 43, 2509$2571(2011)$

3. F. Roberz, R.C.G.M. Loonen, P. Hoes, J.L.M. Hensen, Energy and Buildings, 138, 432-442 (2017)

4. M. Nemecek, M. Kalousek, www.tzb-info.cz

5. STN 73 0540:2012 (2012) 